\title{
Gender Differences in Online High School Courses
}

\author{
Susan Lowes, Peiyi Lin, and Brian R. C. Kinghorn \\ Teachers College, Columbia University
}

\begin{abstract}
Prior research has suggested that there may be differences in the ways that male and female students approach their online courses. Using data for 802 high school students enrolled in 14 online courses, this study explored gender differences in the interrelationships among online behaviors and course performance. The findings show that females were more active than males and that a higher degree of online activity and discussion forum viewing and posting was associated with better final grades, but the correlation was stronger for males than it was for females. Further exploration of posting behaviors revealed that females who received lower final grades were more active than males who received lower grades-they viewed more posts, wrote more posts, and wrote longer posts. These gender differences have implications for researchers, course providers, and course designers.
\end{abstract}

Keywords: online learning, LMS research, gender differences

\section{Introduction}

Online courses generate streams of data from Learning Management Systems (LMS) that can be used to provide insights into student behavior in an online environment, especially as it relates to learning outcomes. Although online learning at the K-12 level has grown rapidly-in 2015, it was estimated that over two million individual students were enrolled in an online course (Watson, Pape, Gemin, \& Vashaw, 2015)_research using LMS data at this level remains sparse (Lowes, 2014), especially compared to the amount of work in higher education. In addition, 
although there is evidence at the college level that males and females may approach these courses differently (Hung, Hsu, \& Rice, 2012; Johnson, 2011; McSporran \& Young, 2001; Rovai, 2001; Tsai, Liang, Hou, \& Tsai, 2015; Yukselturk \& Bulut, 2009), these differences have not been explored to the same extent for high school students. This paper uses LMS data generated by approximately 800 high school students who were enrolled in the 14 asynchronous cohort-paced online courses offered by Pamoja Education (PJE), the course provider for the International Baccalaureate (IB), in order to explore the link between LMS behaviors and course outcomes at the high school level and to further explore intriguing gender differences that we had found in previous research (Lowes, Lin, \& Kinghorn, 2015).

\section{Literature Review}

Online courses at the high school level may be provided by state or district virtual schools, by virtual charter schools, or by private providers. These courses are usually asynchronous but can be either self-paced or follow a cohort-based weekly schedule. The vast majority of these students are taking one or two courses, generally because a course is not offered at their school but also to recover credits for failed or missed courses, to free up their schedules, or to gain experience with an online course before college (International Association for K-12 Online Learning [iNACOL], 2013).

The research using the LMS output generated by these courses has found that higher levels of activity are almost always associated with better outcomes (as measured by final grades) and greater student satisfaction (for a review, see Cho \& Kim, 2013). In looking at this literature, it is useful to adapt a distinction Chapman (2003) made for face-to-face learning, between activity-as-participation-for instance, attending class and submitting assignmentsand activity-as-interaction - the sustained involvement in learning activities involving cognitive, behavioral, and affective aspects. In face-to-face classrooms, activity-as-participation is measured in a number of ways, including attendance, number of homework or other assignments submitted, and time on task. In online courses, the most easily accessible counterparts to these measures are a combination of frequency and duration variables (Morris, Finnegan, \& Wu, 2005): number of logins, number of pages accessed, number of assignments submitted, time spent in the system, etc. In what follows, we will call these attendance variables. For the online counterparts to classroom interaction, the most accessible and frequently used LMS variables are discussion forum posts viewed and discussion forum posts authored. In what follows, we will call these interactivity behaviors. Taken together, these become a measure of overall student engagement in a course.

As researchers, have searched for LMS variables that are associated with success, the types of activity they have analyzed have differed, as have their results. A number of studies have found that only attendance behaviors are correlated with final grades (Ramos \& Yudko, 2008; Ryabov, 2012; Wang \& Newlin, 2000) while other studies have found that it is the interactivity behaviors that are most important (Dawson, McWilliam, \& Tan, 2008; Davies \& Graff, 2005; Hung \& Zhang, 2008; Macfadyen \& Dawson, 2010; Morris, Finnegan, \& Wua, 2005; Wei, Peng, \& Chou, 2015). However, all these studies have been in higher education. To date, there have been very few studies using LMS data at the high school level (Hung, Hsu, \& Rice, 2012; Liu \& Cavanaugh, 2011a, 2011b, 2012). 
Only a few of the researchers at either the college or high school level have looked at gender differences in LMS behaviors, but those who have suggest that there may be differences in how male and female students approach their online courses (Hung, Hsu, \& Rice, 2012; Johnson, 2011; McSporran \& Young, 2001; Rovai, 2001; Yukselturk \& Bulut, 2009). For example, McSporran and Young (2001), analyzing data from a college-level web design course, found that women showed consistently higher levels of activity than males in their online classes, completed more assignments, seemed to be better at self-regulation, and performed better. Similarly, Hung, Hsu, and Rice (2012) also found that females performed better and were more active than males. Johnson (2011), analyzing data from a large information systems course, found that the higher levels of interaction and general sociability among females was an advantage in online courses that was likely to lead to better outcomes for females than males. Tsai, Liang, Hou, and Tsai (2015), comparing online and face-to-face discussions, found that while male and female discussion strategies were similar in face-to-face situations, females had better elaboration skills than males in the online discussions. Our own research (Lowes et al., 2015) found that females were overall more active than males - they logged in more frequently, spent more time when logged in, viewed more discussion forum posts, and did more discussion forum posting. However, all five behaviors explained a larger proportion of the variance in the final grades for males than for females. In addition, interactivity behaviors had a statistically significant relationship with final grades for males only. The lack of a correlation between interactivity, in this case measured by posts viewed and posts written, and higher final grades for females suggested that this interactivity was for some reason not rewarded by better grades.

\section{Objectives}

Taken together, these disparate findings are intriguing because they suggest that females and males may approach their online courses differently. In this paper we wanted to follow up on our own previous work and look more closely at gender differences in the interactivity behaviors in particular. We made two changes to our approach. First, while in our previous work the number of posts authored included posts made to other than the weekly discussions (i.e., Help and General Discussion forums), in this paper we confined the analysis to those discussion posts that are part of course content. The pedagogy underlying the course design is constructivist and assumes that peer interaction is essential to learning (Anderson, 2003; Jonassen, 1999), so focusing on the content-related discussion forums seemed a better gauge of student effort. Second, we broke these discussion forum posts into initial and response posts. We hoped that doing so would provide additional information since students were required to make an initial post to answer a prompt posted by the teacher and tended to do so, but were only strongly encouraged to respond to their classmates' posts. Response posts would therefore seem to indicate a greater commitment to the course. We wanted to know if distinguishing the two types of post writing (initial and response posts) would further our understanding of gender differences in these courses.

The goal of this research is therefore to explore further the gender differences in the interrelationships among LMS behaviors and course performance. We did this using data from a set of asynchronous online courses for high school students. 


\section{Methods}

\section{Setting}

The setting for the study is the entire set of 14 asynchronous online courses offered by Pamoja Education (PJE), the course provider for the International Baccalaureate (IB), in AY 2014-2015. The students were taking these courses as part of the IB Diploma Program (IBDP), a challenging course of study for students in their last two years of high school. Those who pass with good scores generally get college credit, allowing these students to be considered academically equivalent to many college freshmen, although younger. The courses are fully asynchronous and follow a cohort-paced weekly schedule, similar to most online courses in higher education. Some of the courses had only one section, while others had as many as six, for a total of 45 sections of 14 different courses in 9 subject areas, with an average of about 20 students per section. The courses were in the following subject areas: Business Management, Economics, Film, Information Technology in a Global Society, Mathematics, Philosophy, Psychology, Mandarin, and Spanish. Most of the students were taking these courses as part of the IB Diploma, but a few were taking them as single courses. Although the courses last two years, we focused on the first year because that is when the most interaction is expected; in the second year, students spend much of their time writing papers and preparing for exams so there is less interaction overall than in Year 1 . The Year 1 students not only completed readings, wrote essays, and submitted other assignments but were expected to interact with each other in multiple structured, facilitated discussion forums and to engage in multi-week group projects. Discussion forum posts were not graded but discussion forum participation was part of the course evaluation rubric and in that way became part of the final grade. Although it is possible that other interaction behaviors, such as email and chat, would provide additional insights into interactions among students, we did not have access to this data. In addition, the discussion forums were designed to be the venue for interaction.

\section{Data sources}

Pamoja Education provided the first author with access to (de-identified) LMS data and end-of-year grades for all 802 Year 1 students, 492 females and 310 males. The LMS was Desire2Learn (D2L) and the data spanned 32 weeks, from week 2 to week 33 (week 1 was not included because course participation in that week is unsettled and the work is minimal).

\section{Procedure}

While in our previous study, we had LMS data for three attendance behaviors-number of days logged in, number of logins, and session duration (hours spent) - and two interactivity behaviors - number of posts viewed and number of posts authored. In this analysis we separated posts authored into initial posts authored and response posts authored. This was done by copying the discussion forums into Excel, which made it possible to distinguish initial and response posts (see Figure 1). (While we were able to separate number of initial and response posts made to the course discussion forums from those made to the non-lesson-related general discussion forums, the LMS data did not allow us to do that for posts viewed. The numbers for posts viewed is therefore larger than if only the posts viewed for the course discussion forums were considered.) 


\begin{tabular}{|c|c|c|c|c|c|c|c|}
\hline & & & Time & Initial & Reponse & Type & gender \\
\hline \multicolumn{3}{|c|}{ Weekly Reading Activity } & 9117/2014 17:24 & 1 & 0 & initial & female \\
\hline & \multicolumn{2}{|c|}{ Re: Weekly Reading Activity } & 911812014 10:16 & 0 & 1 & response & female \\
\hline \multirow[t]{6}{*}{$\boxminus$} & \multicolumn{2}{|c|}{ Re: Weekly Reading Activity } & 918+2014 11:25 & 0 & 1 & response & female \\
\hline & \multirow[t]{2}{*}{$\boxminus$} & Re: Weekly Reading & 9/19/2014 13:03 & 0 & 1 & response & female \\
\hline & & Re: Weekly & 912012014 14:58 & 0 & 1 & response & female \\
\hline & \multicolumn{2}{|c|}{ Re: Weekly Reading Activity } & $9 / 19 / 20145: 33$ & 0 & 1 & response & female \\
\hline & \multicolumn{2}{|c|}{ Re: Weekly Reading Activity } & $91201201422-54$ & 0 & 1 & response & male \\
\hline & \multicolumn{2}{|c|}{ Re: Weekly Reading Activity } & $9 / 23 / 2014$ 19:25 & 0 & 1 & response & female \\
\hline \multicolumn{3}{|c|}{ Textbook reading Chapter 1} & 911712014 14:54 & 1 & 0 & initial & male \\
\hline \multirow[t]{3}{*}{$\boxminus$} & \multicolumn{2}{|c|}{ Re: Textbook reading Chapter 1} & 9/1812014 10:12 & 0 & 1 & response & female \\
\hline & \multicolumn{2}{|c|}{ Re: Textbook reading } & $9 / 201201414: 40$ & 0 & 1 & response & female \\
\hline & \multicolumn{2}{|c|}{ Re: Textbook reading Chapter 1} & $9 / 19+2014$ 5:35 & 0 & 1 & response & female \\
\hline
\end{tabular}

Figure 1. Screenshot of initial and response posts

\section{Analysis}

Multivariate analysis was performed to investigate gender differences among the online behaviors and course performance. Course grades in IB courses are ordinal, ranging from 1 to 7. Those who received 4-7 passed and those who received 1-3 did not. The six behaviors were averaged across 31 weeks (weeks 2 - 32) and standardized. We conducted structural equation modeling (SEM) for the analysis. We then looked in depth at the interactivity behaviors by gender and final course grade, and, in a case study of one course, looked at post length as an additional behavior.

\section{Results}

\section{Gender differences in course performance}

We used SPSS 23 to see if there was a difference in final grade by gender (Table 1$)$. The results show that females on average earned higher final grades than males, $t(800)=3.365, p=$ $.0008(p<.001)$; the difference was medium or typical (Cohen’s $d=.244$ ).

Table 1

Means and Standard Deviations for Course Grades by Gender

\begin{tabular}{lccc}
\hline & $N$ & $M$. & $S D$. \\
\hline All & 802 & 4.7 & 1.7 \\
Female & 492 & 4.9 & 1.6 \\
Male & 310 & 4.5 & 1.7 \\
\hline
\end{tabular}

Note that the final grade can also be considered ordinal (i.e., rank). If we instead use the non-parametric approach to examine the difference in final grade by gender, a Mann-Whitney U test also shows that females performed better $(M d n=5)$ than males $(M d n=4), U=66052.500, p$ $=.001(p<.01), r=.115$. In addition, the 1st quartile (25\% percentile) was 4 for females and 3 for males and the 3rd quartile (75\% percentile) was 6 for both genders. 


\section{Bivariate correlations between course behaviors and course performance}

The average course behaviors and standard deviations show that students on average logged in several times a week for four hours, viewed eight posts, and wrote 0.5 initial posts and 0.4 response posts (note that there are not discussion forum topics every week). However, there was a large range among students. Females were more active than males in terms of days and logins per week, but not in terms of time spent (Table 2). However, hours spent is the least precise of the behavioral measures because we do not know what a student was doing when logged in. The system does have an automatic log out after 20 minutes, but it still may be the case that time spent is overestimated. As noted above, there were no specific requirements for discussion forum contributions, just a strong suggestion to make one initial post and at least one response, with the degree of engagement in the discussion forums factored into final grades. Females on average had more posts viewed, and more initial and response posts authored.

Table 2

Course Behaviors Averaged by Week by Gender

\begin{tabular}{|c|c|c|c|c|c|c|c|c|c|c|c|c|}
\hline & \multicolumn{2}{|c|}{ Days } & \multicolumn{2}{|c|}{$\underline{\text { Logins }}$} & \multicolumn{2}{|c|}{$\underline{\text { Hours }}$} & \multicolumn{2}{|c|}{ Posts viewed } & \multicolumn{2}{|c|}{$\underline{\text { Initial posts }}$} & \multicolumn{2}{|c|}{ Response posts } \\
\hline & $M$. & $S D$. & M. & $S D$. & M. & $S D$. & $M$. & $S D$. & $M$. & $S D$. & $M$. & $S D$. \\
\hline All & 3.2 & 1.1 & 6.5 & 3.2 & 3.9 & 2.6 & 8.0 & 9.4 & 0.5 & 0.3 & 0.4 & 0.5 \\
\hline Female & 3.2 & 1.0 & 6.6 & 2.9 & 3.9 & 2.1 & 8.7 & 9.8 & 0.5 & 0.3 & 0.5 & 0.5 \\
\hline Male & 3.1 & 1.1 & 6.3 & 3.5 & 4.1 & 3.1 & 7.0 & 8.5 & 0.4 & 0.3 & 0.4 & 0.5 \\
\hline
\end{tabular}

Using the non-parametric approach (Spearman's $\rho$ ), there is strong evidence that there are correlations between each course behavior and final grade $(p<.001$ for all) but the correlations are always stronger for males than for females (Table 3). This suggests that although, as we have seen, females are more active, that activity does not translate into higher grades.

Table 3

Correlation Between Course Behaviors and Final Grade by Gender

\begin{tabular}{lcclcccc}
\hline & $N$ & Days & Logins & Hours & Posts viewed & Initial posts & Response posts \\
\hline All & 802 & $.387^{* * *}$ & $.337^{* * *}$ & $.350^{* * *}$ & $.293^{* * *}$ & $.335^{* * *}$ & $.365^{* * *}$ \\
Female & 492 & $.372^{* * *}$ & $.295^{* * *}$ & $.303^{* * *}$ & $.237^{* * *}$ & $.282^{* * *}$ & $.306^{* * *}$ \\
Male & 310 & $.405^{* * *}$ & $.388^{* * *}$ & $.421^{* * *}$ & $.357^{* * *}$ & $.389^{* * *}$ & $.415^{* * *}$ \\
\hline \multicolumn{2}{l}{ Note: ${ }^{* * * *} p<.001}$.
\end{tabular}

\section{Modeling course behaviors and course performance}

We next used Mplus 7.3 (Muthén \& Muthén, 1998-2015) to conduct structural equation modeling (SEM) to look further into the interrelationships among LMS behaviors and course performance. The weighted least squares estimator (WLSMV) was selected for estimation as the outcome variable (i.e., final course grade) was ordinal and had a strong ceiling effect. The relationships among attendance behaviors, interactivity behaviors, and final grade can be described in two conceptual models, one with the six behaviors explaining a single latent factor ("engagement") and the other with three behaviors explaining one latent factor ("attendance") and three behaviors explaining a second latent factor ("interactivity"). Figure 2 below shows the two conceptual models. The model specifications include three freely estimated relationships between \# days and \# logins, \# logins and \# hours, and \# initial posts and response posts in order 
to deal with the fact that the LMS variables are not measured independently. For instance, \# days and \# logins are inclusive.
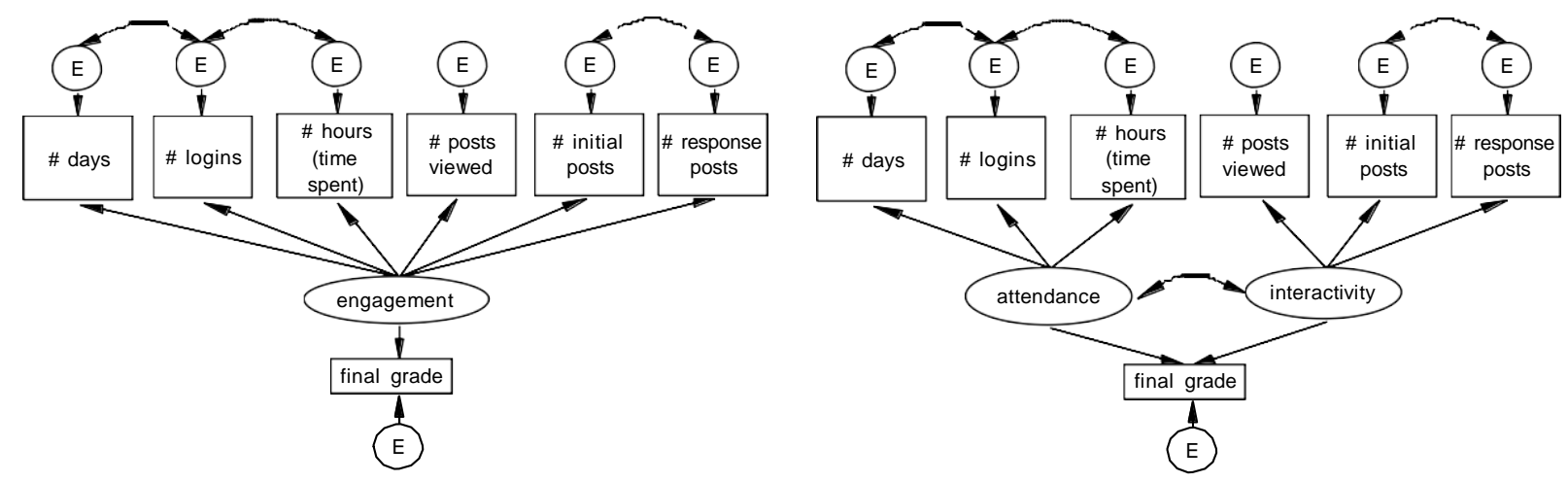

Figure 2. One-factor and two-factor models for the relationship between course behaviors and final grade.

Table 4 summarizes the model fit indices for the one- and two-factor models, first without gender and then with gender considered in a multiple-group analysis. The indices show that the two-factor models (both with and without gender) provide a better fit for our data than the one-factor models that consider the six behaviors as the same type. In addition, the two-factor model that considers gender is better than the two-factor model without gender. (The Chi-square contribution is 36.204 for males and 24.683 for females.) We therefore focus on the two-factor models in the sections that follow.

Table 4

Model Fit Indices

\begin{tabular}{lccccccc}
\hline Model & $X^{2}$ & $d f$ & Sig. of $X^{2}$ & RMSEA (90\% CI) & CFI & TLI & WRMR \\
\hline 1-F (no gender) & 294.511 & 10 & $<.0001$ & $.188(.170-207)$ & .886 & .760 & 1.635 \\
1-F (with gender) & 202.795 & 30 & $<.0001$ & $.120(.105-.136)$ & .923 & .893 & 1.738 \\
2-F (no gender) & 43.917 & 9 & $<.0001$ & $.070(.050-.091)$ & .986 & .967 & .491 \\
2-F (with gender) & 60.887 & 27 & .0002 & $.056(.037-.075)$ & .985 & .977 & .777 \\
\hline
\end{tabular}

Two-factor model with gender not considered. When we look at both genders together, there is strong evidence to suggest that higher levels of attendance and higher levels of interactivity both increased the predicted probability of higher final grades $\left(\gamma_{11}=.315, p<.001\right.$; $\left.\gamma_{12}=.211, p<.001\right)$, with attendance having a stronger relationship with final grade than interactivity (Figure 3). The error variances for the six behaviors are statistically significant $(p<$ .001 for all) except for number of days $(p=.011, p<.05)$. 


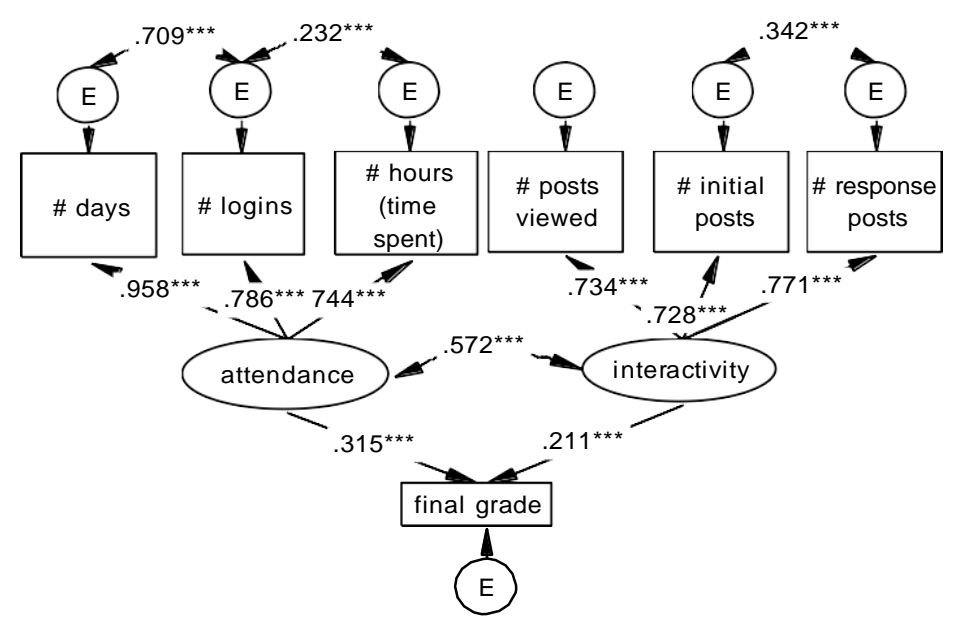

Figure 3. Standardized parameter estimates for the two-factor, no-gender model.

Two-factor model with gender considered. When we take gender into consideration, we find that there are differences in the interrelationships among course behaviors and course performance (Figure 4). First, females' attendance pattern is best described by days accessed and hours spent, while males' attendance pattern is best described by days accessed and logins. The residual variance for days accessed for males is found to be negative-a Heywood case - and is not statistically significant $(p>.05)$ and then set at zero. The negative residual variance is likely due to this variable for males being highly skewed and had a floor effect (Muthén, 2005). The model modification made males' attendance measured by days. While this may point to model specification issues, it should be noted that the negative residual variance is small. This is further evidence of gender differences in learning and how we assess them.

Second, females' interactivity pattern is best explained by two equally important behaviors, initial and response posts, while males' interactivity pattern is best explained by one behavior, posts viewed.

In terms of the relationships between the two factors and final grade, higher levels of attendance and higher levels of interactivity increase the predicted probability of higher final grades for both males $\left(\gamma_{11}=.346, p<.001, \gamma_{12}=.247, p<.001\right.$, respectively) and females $\left(\gamma_{11}=\right.$ $.323, p<.001 ; \gamma_{12}=.153, p<.05$, respectively). However, when we look at the magnitude of the relationships, we find that the coefficient from interactivity to final grade is noticeably smaller for females than for males. In other words, the amount of work that females put into interactivity does not help explain their course performance to the extent that it does for males. 
Females

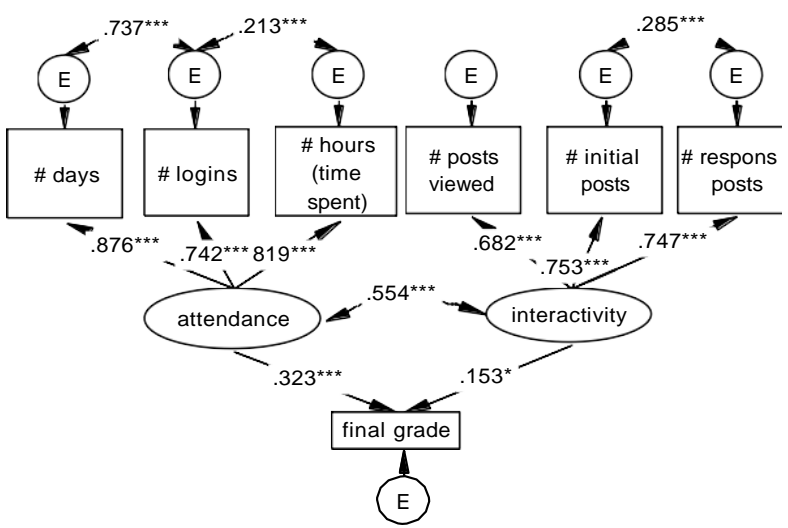

Males

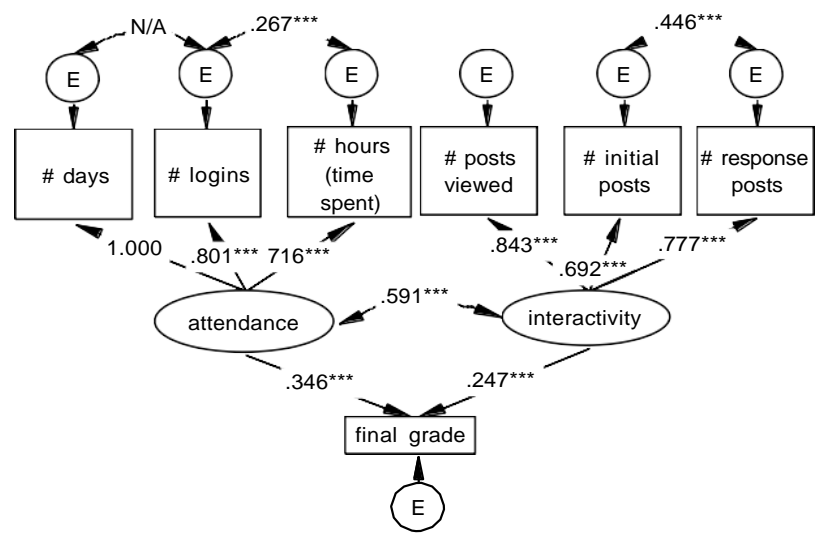

Figure 4. Standard parameter estimates for the two-factor models by gender.

Two-factor models with and without gender compared. When we compare the models with and without gender (Table 5), we find that the model considering gender reveals differences between females and males that we do not see unless gender is considered.

Table 5

Comparison of Standard Parameter Estimates by Gender

\begin{tabular}{|c|c|c|c|c|c|c|c|c|c|}
\hline & \multicolumn{3}{|c|}{ "Attendance" } & \multicolumn{3}{|c|}{ "Interactivity" } & \multirow{2}{*}{$\begin{array}{c}\text { Factor } \\
\text { corr. }\end{array}$} & \multicolumn{2}{|c|}{ Coefficients on final grade } \\
\hline & Days & Logins & Hours & Viewed & Initial & Response & & "Attendance" & "Interactivity" \\
\hline All & $.958 * * *$ & $.786 * * *$ & $.744^{* * *}$ & $.734^{* * *}$ & $.728^{* * *}$ & $.771 * * *$ & $.572 * * *$ & $.315 * * *$ & $.211 * * *$ \\
\hline Female & $.876 * * *$ & $.742 * * *$ & $.819 * * *$ & $.682^{* * *}$ & $.753^{* * *}$ & $.747 * * *$ & $.554 * * *$ & $.323 * * *$ & $.153^{*}$ \\
\hline Male & 1.000 & $.801^{* * *}$ & $.716^{* * *}$ & $.843^{* * *}$ & $.692 * * *$ & $.777 * * *$ & $.591 * * *$ & $.346 * * *$ & $.247 * * *$ \\
\hline
\end{tabular}

In addition, when we compare the $R$-squared information of the models with and without gender (Table 6), we find that the no-gender model explains 22 percent the total variance in the students' final grade, but that the model with gender explains 28 percent of the total variance in final grade for males but a much lower 18 percent for females. As discussed above, the difference is the result of differences in the interactivity behaviors.

Table 6

$R$-squared Information by Gender

\begin{tabular}{lc}
\hline & $R^{2}$ \\
\hline All & .220 \\
Female & .182 \\
Male & .282 \\
\hline
\end{tabular}

The lack of consistency between females' interactivity behaviors and their final grades suggested that it might be helpful to look at course behaviors and performance in more detail.

\section{Interactivity behaviors by final grade}

We first looked at the total number of posts viewed and authored for the 31 weeks (weeks 2-32) by gender and found that females on average viewed a total of 300 posts, wrote 15 initial posts, and authored 15 response posts (Table 7)—more than males for all three behaviors. 
Table 7

Total Average Viewing and Posting Behaviors by Gender

\begin{tabular}{|c|c|c|c|c|c|c|}
\hline & \multicolumn{2}{|c|}{ Posts viewed } & \multicolumn{2}{|c|}{$\underline{\text { Initial posts }}$} & \multicolumn{2}{|c|}{$\underline{\text { Response posts }}$} \\
\hline & M. & $S D$. & M. & SD. & M. & $S D$. \\
\hline Female & 300 & 337 & 15 & 9 & 15 & 17 \\
\hline Male & 241 & 297 & 13 & 10 & 12 & 17 \\
\hline
\end{tabular}

Next we looked at the total number of posts viewed and authored over the entire 31 weeks by gender for each final grade. Females almost always viewed more posts than males, no matter what their final grade (Figure 5). For example, females who received a grade of 1 viewed more than twice as many posts over 31 weeks as males who received a grade of 1 . Most important of all, the differences between males and females are greatest for those with lower grades. For example, females who received a grade of 1 on average viewed 112 posts and males viewed a total of 46 .

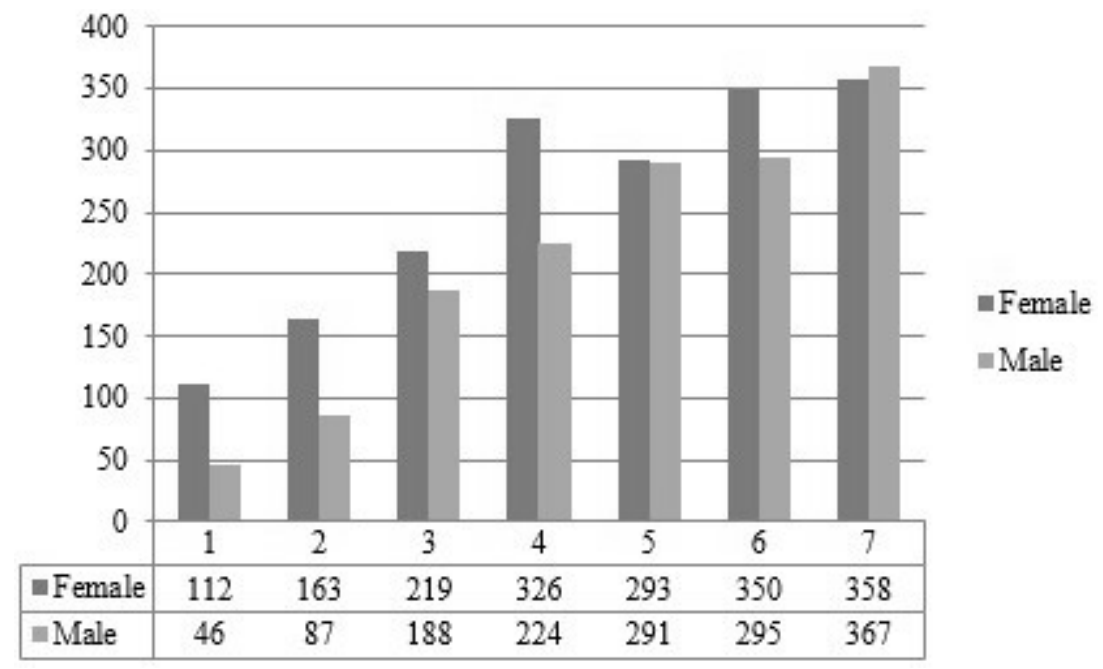

Figure 5. Average number of all posts viewed by gender.

This difference is also evident in the initial posts and response posts (Figures 6 and 7). Again, the differences between the genders are greatest for those who received lower grades.

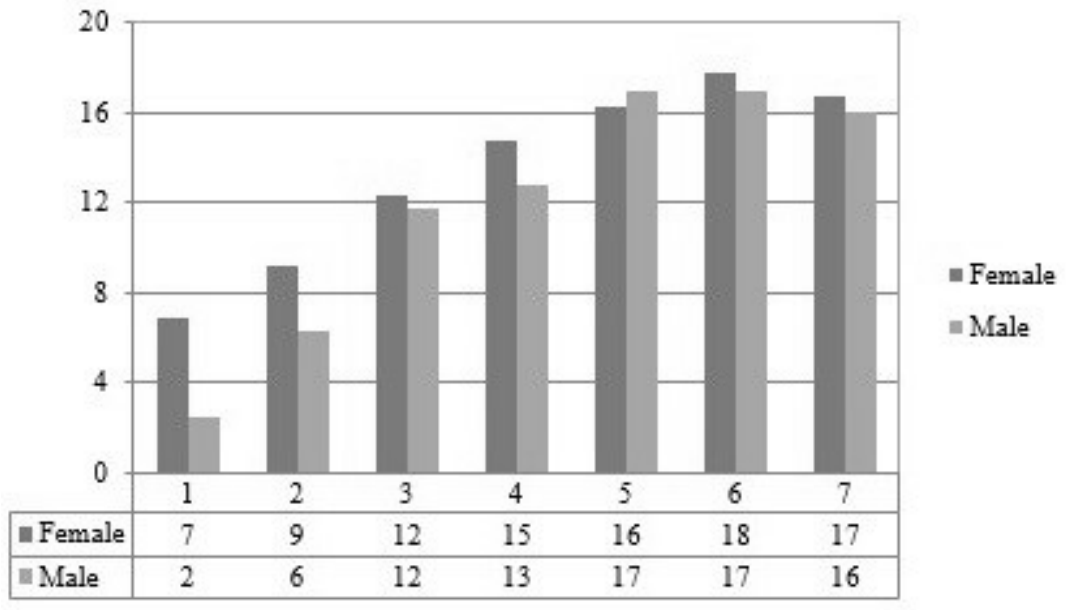


Figure 6. Average number of all initial posts authored by gender.

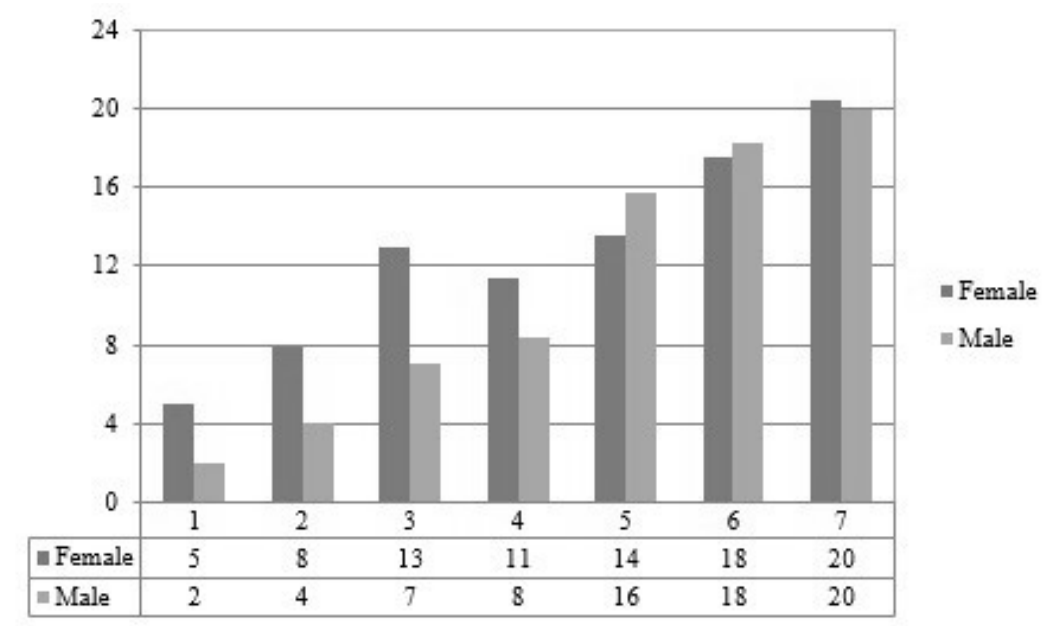

Figure 7. Average number of all response posts authored by gender.

Looking at interactivity behaviors by final grade and by gender shows that not only were females more active overall, but females who received lower grades were much more active than their male counterparts and that there was an increasing trend for males that was not as evident for females.

\section{Post length: A case study}

If females were posting more, were they writing longer posts? After all, in terms of the amount of effort put into posting, they could be posting more but making shorter posts. Retrieving the data needed to investigate post length (i.e., by counting words) from an LMS is extremely time consuming, so we began with a case study of one course. We selected an Economics course that had a relatively balanced gender ratio, with a total of 67 students (48 percent females and 52 percent males) in four sections. Table 8 below compares the descriptive statistics for the Economics sample to the entire group. As Economics has a heavy workload, it is not surprising that these students were more active than the entire group for all behaviors.

Table 8

Comparison of Descriptives for LMS Behaviors Between Entire Cohort and Economics Students

\begin{tabular}{|c|c|c|c|c|c|c|c|c|c|c|c|c|}
\hline & \multicolumn{2}{|c|}{$\underline{\text { Days }}$} & \multicolumn{2}{|c|}{$\underline{\text { Logins }}$} & \multicolumn{2}{|c|}{$\underline{\text { Hours }}$} & \multicolumn{2}{|c|}{$\underline{\text { Posts viewed }}$} & \multicolumn{2}{|c|}{$\underline{\text { Initial posts }}$} & \multicolumn{2}{|c|}{$\underline{\text { Response posts }}$} \\
\hline & M. & $S D$. & M. & $S D$. & M. & $S D$. & M. & $S D$. & $M$. & $S D$. & $M$. & $S D$. \\
\hline Cohort & 3.2 & 1.1 & 6.5 & 3.2 & 3.9 & 2.6 & 8.0 & 9.4 & 0.5 & 0.3 & 0.4 & 0.5 \\
\hline Economics & 3.5 & 1.3 & 7.3 & 3.9 & 5.3 & 3.8 & 11.9 & 12.5 & 0.7 & 0.4 & 0.8 & 0.8 \\
\hline
\end{tabular}

However, when we examine the behaviors by gender (Table 9), we find that the fact that the Economics students were more active than the entire cohort is largely due to the females' participation. 
Table 9

Comparison of Descriptives for LMS Behaviors for Economics by Gender

\begin{tabular}{|c|c|c|c|c|c|c|c|c|c|c|c|c|}
\hline & \multicolumn{2}{|c|}{ Days } & \multicolumn{2}{|c|}{ Logins } & \multicolumn{2}{|c|}{$\underline{\text { Hours }}$} & \multicolumn{2}{|c|}{ Posts viewed } & \multicolumn{2}{|c|}{$\underline{\text { Initial posts }}$} & \multicolumn{2}{|c|}{ Response posts } \\
\hline & $M$. & $S D$. & $M$ & $S D$. & $M$. & $S D$. & $M$. & $S D$. & $\bar{M}$. & $\overline{S D}$. & $M$. & $S D$. \\
\hline Female & 3.9 & 1.1 & 7.9 & 2.7 & 5.2 & 2.1 & 16.9 & 14.7 & 0.8 & 0.4 & 1.0 & 0.9 \\
\hline Male & 3.1 & 1.4 & 6.8 & 4.7 & 5.3 & 4.9 & 7.3 & 7.8 & 0.6 & 0.4 & 0.7 & 0.6 \\
\hline
\end{tabular}

During the 31 weeks, there were 39 discussion topics. Initial posts were much longer than response posts — not surprising since the students were responding to a specific prompt — but for both initial and response posts, females wrote more than males (Table 10).

Table 10

Comparison of Post Length by Gender for Economics

\begin{tabular}{|c|c|c|c|c|}
\hline & \multicolumn{2}{|c|}{ Initial posts } & \multicolumn{2}{|c|}{ Response posts } \\
\hline & $\bar{M}$ & $S D$. & M. & $S D$. \\
\hline Female & 105 & 71 & 18 & 16 \\
\hline Male & 87 & 59 & 13 & 15 \\
\hline
\end{tabular}

This was the case in almost all of the 31 weeks (Figure 8 on the next page).

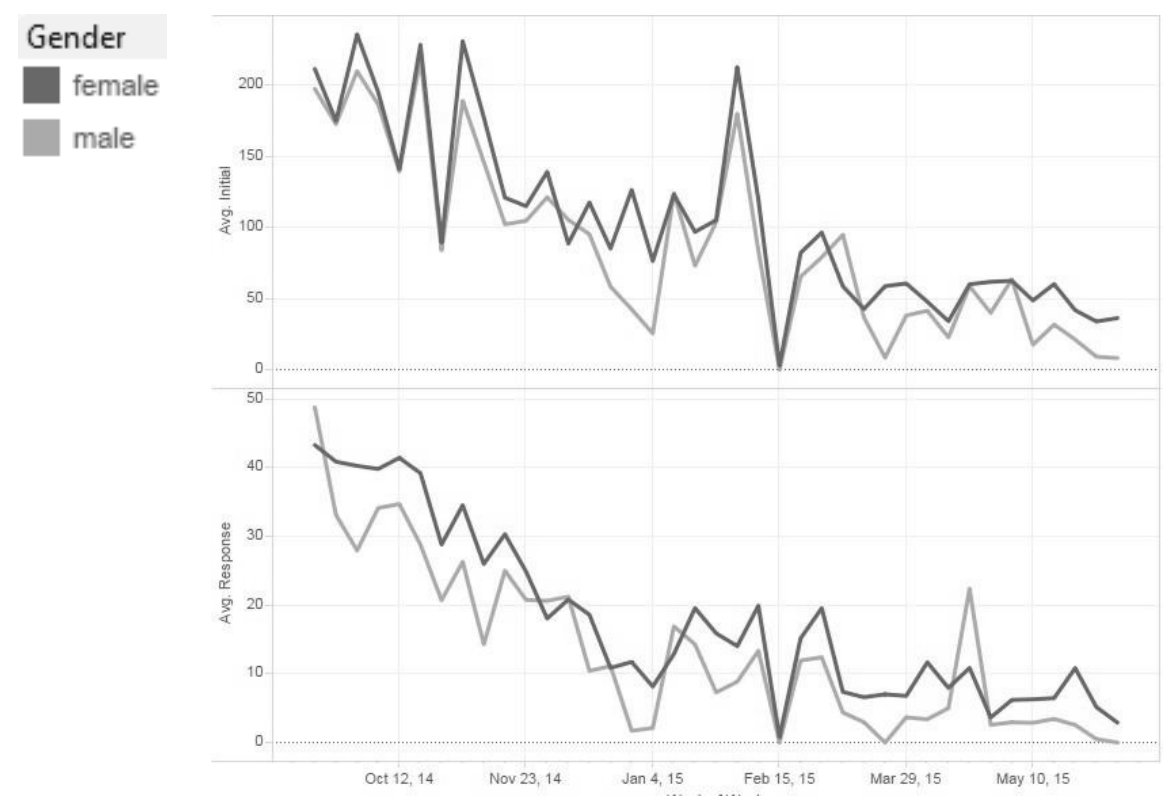

Figure 8. Initial and response posts by week. 
However, when we look at this aspect of posting for each grade given (Figures 9 and 10), the trends for this small set of students are the same: it is still true that females with low grades wrote longer responses posts than males with low grades. Since the numbers are small, we cannot generalize with confidence from these results; we expect that larger numbers would provide a clearer picture.

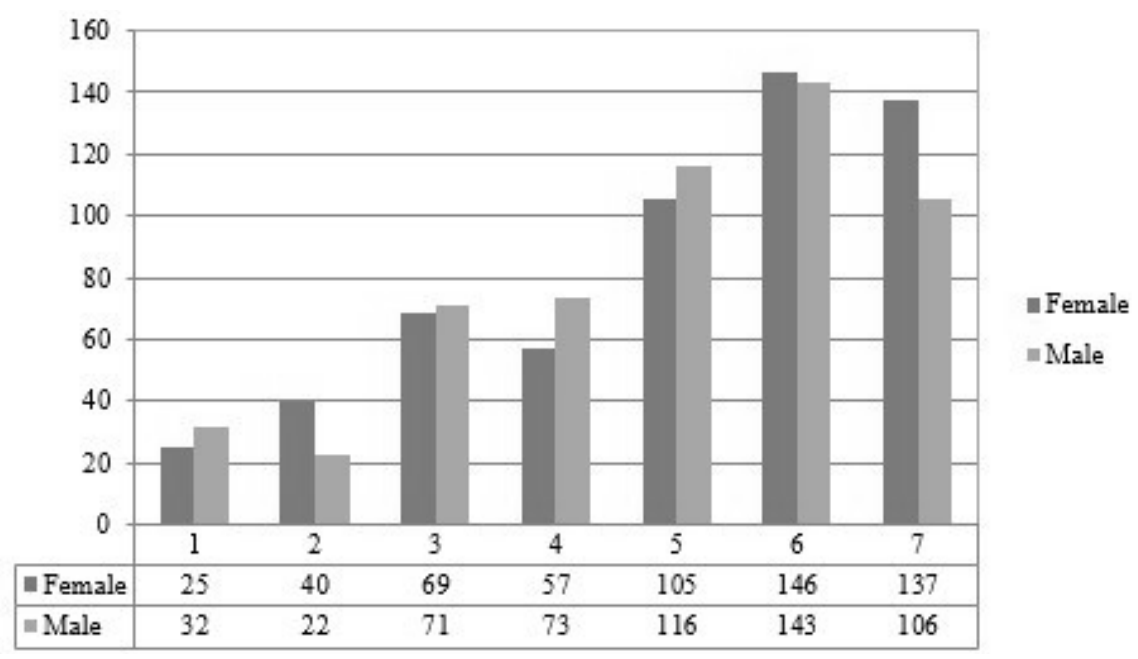

Figure 9. Post length for initial posts by gender and grade for Economics.

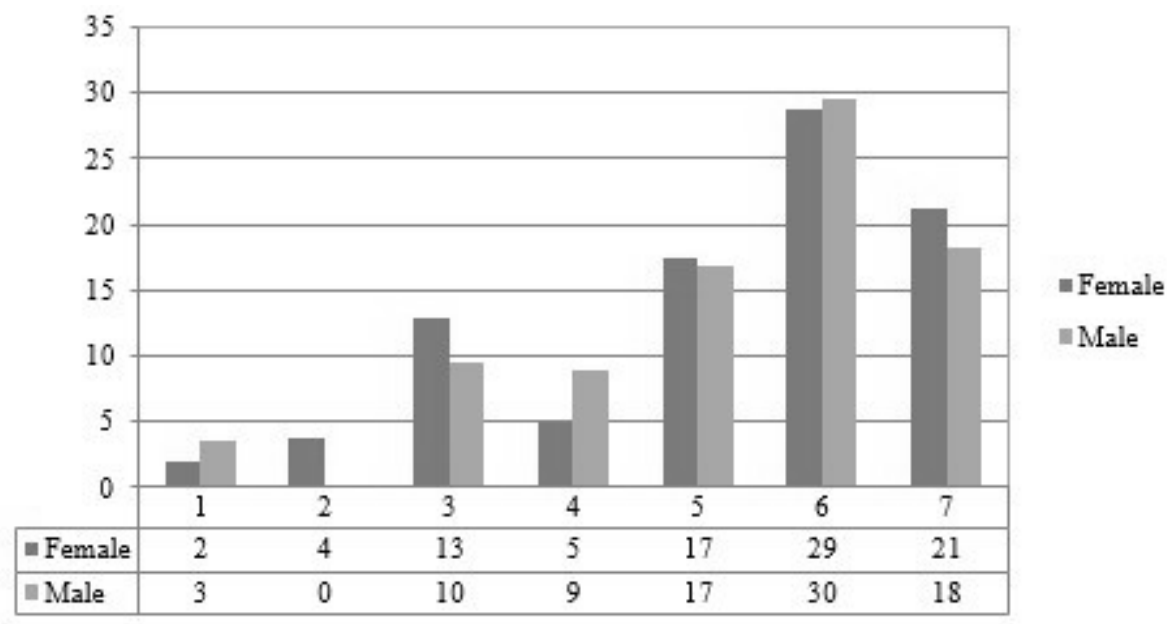

Figure 10. Post length for response posts by gender and grade for Economics.

The goal of the case study was to investigate whether post length might help us better understand female activity. We found that females wrote longer posts than males overall and that the gender differences were greater for those receiving lower grades. However, to see if these findings hold across all courses, we would need an easier method for capturing post length than word counts done by hand. 


\section{Summary and Implications}

This study builds on previous work investigating gender differences in the interrelationships among LMS behaviors and course performance (Lowes et al., 2015). Our findings in that study were consistent with research that found that the effort that students put into their online courses is positively correlated with higher final grades. However, we also found that the correlations were not the same for females and males. Whether we considered the five LMS behaviors (number of days accessed, logins, session duration measured as hours spent, posts viewed, posts authored) as one behavior (i.e., all five representing overall course engagement) or as two distinct types of online behavior (i.e., three representing attendance and two representing interactivity), these online behaviors accounted for a larger proportion of the total variance in course performance for males than females. In particular, there was a lack of correlation between interactivity behaviors (viewing and writing posts) and final grades for females. This seemed to suggest that on average, what might be considered female diligence in the discussion forums was not rewarded by higher grades.

Since it seemed possible that using all discussion forum activity rather than focusing on the activity most closely related to learning could have affected our results, in this study we confined ourselves to data from those discussion forums that were part of the weekly course lessons. And since posting responses seems to indicate a higher level of engagement than initial posts, we manually separated posts authored into initial and response posts. This gave us six LMS behaviors, three relating to attendance and three relating to interactivity. We found that post viewing best explains males' interactivity pattern and post writing best explains females' interactivity pattern. This suggests that males and females may approach discussion forums differently. In addition, interactivity behaviors had a stronger correlation with final grade for males than for females. This again suggests different strategies. For example, males may respond to the first posts they come to, an economical strategy in terms of use of time. Females, on the other hand, may view several posts before they choose which one to respond to. This in turn suggests that females are not only more diligent but may also be more intent on creating community while males are focused on the end result.

To further investigate these gender differences, we next compared the three interactivity behaviors by final grade and found that the differences by gender were larger for those who earned lower grades. In other words, females who earned lower grades had higher levels of interactivity than males who earned lower grades, suggesting that their activity is not equally rewarded, at least in terms of final grades, but also that communication with peers may be more important to females than to males.

The next question was whether females' posting more also meant that they were writing more. We therefore examined post length, using one course as an example. This showed that females not only viewed and authored more posts than males but that their posts were longer as well. Data visualization over time showed that this was the case in almost every week over the course of the year, indicating that these differences in behaviors are not episodic but are aspects of the gendered approach to this type of learning.

These gender differences lead to suggestions for researchers, providers, course designers, and teachers. Researchers who are analyzing LMS data need to be on the alert for gender 
differences and build comparisons by gender into their analyses. In addition, those interested in using online behaviors to estimate learning outcomes need to consider gender since such estimates are likely to be more accurate for males than females. Those designing or teaching online courses need to be equally aware of gender differences. For example, if peer interaction is a goal, then this needs to be guided and rewarded. In this particular case, if formal credit had been given for the discussion forum postings, taking both frequency and depth into consideration, males might have spent more time writing posts and females might have been given more credit for the time they did put in. Course designers who consider student-student interaction to be important may need to give clear guidelines about effective approaches to reading and posting in forums while those teaching online courses may need to remind students that all students need to engage in discussions. In addition, students who are doing poorly but are active in the discussion forums - perhaps because these are easier than other assignments - may need suggestions for better time management strategies.

\section{Limitations and Directions for Future Research}

There are several limitations to generalizing this research to other contexts. First, students taking IB courses tend to be college-bound and highly motivated, so these findings may not be applicable to other populations of high school students. Second, we only had access to a small number of LMS variables to measure attendance and interactivity. Adding more attendance variables, such as assignments submitted, or interactivity variables, such as non-discussion forum student-student interaction, might change the interrelationships among behaviors and final grades. Finally, we need to be careful not to reify "female" and "male" behaviors, since there is considerable variability among those identified as male and those identified as female (binary categories taken from the student information system).

In terms of future research, it seems clear that there are measurable differences between male and female behaviors but the precise nature of these differences needs further exploration. For example, a qualitative approach that looked in depth at the content of the posts could explore whether females are more diligent no matter how well they are doing in the course or whether they are simply more sociable (Arbaugh, 2000; Johnson, 2011; Rovai, 2001), with this being the reason that their posting behavior did not explain as much of their final grades. Similarly, for males: Are they writing less because their writing is more concise and efficient or because they put their effort into aspects of the course work that they believe will have a larger impact on their final grades? It would also be interesting to know if there are gendered differences in how males and females proceed through a course - where they go first, for example-and how long they spend on each activity. Time-stamped data might make this possible. Whatever the direction, it seems clear that gender difference is a fruitful area for future research.

\section{Acknowledgments}

The authors would like to thank Pamoja Education for its willingness to provide the data that made this analysis possible and for its support of the effort to make sense of it, and the journal reviewers for their helpful comments and suggestions. 


\section{References}

Anderson, T. (2003). Getting the mix right again: An updated and theoretical rationale for interaction. The International Review of Research in Open and Distributed Learning, 4(2). http://www.irrodl.org/index.php/irrodl/article/view/149/230

Arbaugh, J. B. (2000). An exploratory study of the effects of gender on student learning and class participation in an Internet-based MBA course. Management Learning, 31(4), 503519. http://dx.doi.org/ 10.1177/1350507600314006

Chapman, E. (2003). Alternative approaches to assessing student engagement rates. Practical Assessment, Research \& Evaluation, 8(13). http://PAREonline.net/getvn.asp?v=8\&n=13

Cho, M. H., \& Kim, B. J. (2013). Students' self-regulation for interaction with others in online learning environments. The Internet and Higher Education, 17, 69-75. http://dx.doi.org/10.1016/j.iheduc.2012.11.001

Davies, J., \& Graff, M. (2005). Performance in e-learning: Online participation and student grades. British Journal of Educational Technology, 35(4), 657-663. http://dx.doi.org/10.1111/j.1467-8535.2005.00542.x

Dawson, S., McWilliam, E., \& Tan, J. (2008). Teaching smarter: How mining ICT data can inform and improve learning and teaching practice. Hello! Where are you in the landscape of educational technology? Proceedings ASCILITE Melbourne 2008 (pp. 221230). http://www.ascilite.org/conferences/melbourne08/procs/dawson.pdf

Hung, J.-L., \& Zhang, K. (2008). Revealing online learning behaviors and activity patterns and making predictions with data mining techniques in online teaching. MERLOT Journal of Online Learning and Teaching, 4(4), 426-437.

http://jolt.merlot.org/vol4no4/hung_1208.pdf

Hung, J., Hsu, Y., \& Rice, K. (2012). Integrating data mining in program evaluation of K-12 online education. Educational Technology \& Society, 15(3), 27-41. http://www.ifets.info/journals/15_3/3.pdf

iNACOL (International Association for K-12 Online Learning). (2013). Fast facts about online learning. Vienna, VA: International Association for Online Learning. http://www.inacol.org/resource/fast-facts-about-online-learning/

Johnson, R. D. (2011). Gender differences in e-learning: Communication, social presence, and learning outcomes. Journal of Organization and End User Computing, 23(1), 79-94. http://dx.doi.org/10.4018/joeuc.2011010105

Jonassen, D. H. (1999). Designing constructivist learning environments. In C. M. Reigeluth (Ed.), Instructional-design theories and models: A new paradigm of instructional theory (Vol. II, pp. 215-39). Mahwah, NJ: Lawrence Erlbaum Associates. 
Liu, F., \& Cavanaugh, C. (2011a). High enrollment course success factors in virtual school: Factors influencing student academic achievement. International Journal on E-Learning, 10(4), 393-418. https://www.learntechlib.org/p/33040/article_33040.pdf

Liu, F., \& Cavanaugh, C. (2011b). Success in online high school Biology: Factors influencing student academic performance. Quarterly Review of Distance Education, 12(1), 37-54. https://rtsdettf.wikispaces.com/file/view/onlineHSBio.pdf

Liu, F., \& Cavanaugh, C. (2012). Factors influencing student academic performance in online high school Algebra. Open Learning: The Journal of Open, Distance and e-Learning, 27(2), 149-167. http://www.tandfonline.com/doi/abs/10.1080/02680513.2012.678613

Lowes, S. (2014). A brief look at the methodologies used in researching online teaching and learning. In R. E. Ferdig \& K. Kennedy (Eds.), Handbook of research on K-12 online and blended learning (pp. 83-104). Pittsburgh, PA: ETC Press.

Lowes, S., \& Lin, P. (2015). Learning to learn online: Using locus of control to help students become successful online learners. Journal of Online Learning Research, 1(1), 17-48. https://www.learntechlib.org/d/149845

Lowes, S., Lin, P., \& Kinghorn, B. (2015). Exploring the link between online behaviours and course performance in asynchronous online high school courses. Journal of Learning Analytics, 2(2), 169-194. http://dx.doi.org/10.18608/jla.2015.22.13

Macfadyen, L. P., \& Dawson, S. (2010). Mining LMS data to develop an "early warning system" for educators: A proof of concept. Computers \& Education, 54(2), 588-599. http://dx.doi.org/10.1016/j.compedu.2009.09.008

McSporran, M., \& Young, S. (2001). Does gender matter in online learning? Research in Learning Technology, 9(2), 3-15.

Morris, L. V., Finnegan, C., \& Wu, S-S. (2005). Tracking student behavior, persistence, and achievement in online courses. Internet and Higher Education, 8, 221-231.

Muthén, L. K. (2005, November 27). Negative Residual Variance [Msg 4]. Message posted to http://www.statmodel2.com/discussion/messages/11/555.html?1358188287.

Muthén, L. K., \& Muthén, B. O. (1998-2015). Mplus User’s Guide. Seventh Edition. Los Angeles, CA: Muthén \& Muthén. https://www.statmodel.com/download/usersguide/Mplus\%20user\%20guide\%20Ver_7_r3 web.pdf

Ramos, C., \& Yudko, E. (2008). "Hits" (not "Discussion Posts") predict student success in online courses: A double cross-validation study. Computers \& Education, 50(4), 11741182. http://dx.doi.org/10.1016/j.compedu.2006.11.003 
Rovai, A. P. (2001). Building classroom community at a distance: A case study. Educational Technology Research and Development, 49(4), 33-48. http://dx.doi.org/10.1007/BF02504946

Ryabov, I. (2012). The effect of time online on grades in online sociology courses. MERLOT Journal of Online Learning and Teaching, 8(1), 13-23. http://jolt.merlot.org/vol8no1/ryabov_0312.htm

Tsai, M.-J., Liang, J.-C., Hou, H.-T., \& Tsai, C.-C. (2015). Males are not as active as females in online discussion: Gender differences in face-to-face and online discussion strategies. Australasian Journal of Educational Technology, 31(3), 263-277. http://ajet.org.au/index.php/AJET/article/view/1557/1278

Wang, A. Y., \& Newlin, M. H. (2000). Characteristics of students who enroll and succeed in psychology web-based classes. Journal of Educational Psychology, 92(1), 137-143.

Watson, J., Pape, L., Gemin, B., \& Vashaw, L. (2015). Keeping pace with K-12 digital learning. Durango, CO: Evergreen Educational Group. http://www.inacol.org/wpcontent/uploads/2015/11/Keeping-Pace-2015-Report.pdf

Wei, H.-C., Peng, C., \& Chou, C. (2015). Can more interactivity improve learning achievement in an online course? Effects of college students' perception and actual use of a coursemanagement system on their learning achievement. Computers \& Education, 83, 10-21. http://dx.doi.org/10.1016/j.compedu.2014.12.013

Yukselturk, E., \& Bulut, S. (2009). Gender differences in self-regulated online learning environments. Educational Technology \& Society, 12(3), 12-22. http://www.ifets.info/journals/12_3/3.pdf 